\title{
CRP LEVELS AND ENDOTHELIAL FUNCTION IN YOUNG WOMEN WITH PCOS
}

\author{
K. Neelaveni', Rajeev Menon², Rakesh Kumar Sahay³, G. Chandrasekhara Reddy ${ }^{4}$ \\ ${ }^{1}$ Associate Professor, Department of Endocrinology, Osmania Medical College, Hyderabad. \\ ${ }^{2}$ Consultant Cardiologist, Care Hospitals, Hyderabad. \\ 3 Professor, Department of Endocrinology, Osmania Medical College, Hyderabad. \\ ${ }^{4}$ Former Professor and HOD, Department of Endocrinology, Osmania Medical College, Hyderabad.
}

\section{ABSTRACT}

\section{BACKGROUND}

PCOS women have a clustering of cardiovascular risk factors and may be at increased risk for cardiovascular disease. Presence of endothelial dysfunction and low grade chronic inflammation may be indicators of early preclinical atherosclerosis in them.

\section{OBJECTIVE}

To assess C-Reactive Protein (CRP) and endothelial function in young women with PCOS.

\section{MATERIALS AND METHODS}

Sixty young women with PCOS (mean age 20.53 years) and fifty control women (mean age 20.26 years) matched as a group for age and BMI were studied. A complete hormonal assay, usCRP, and other laboratory parameters of insulin resistance, glycaemic, cholesterol status were studied in each subject. Endothelium dependent vascular function was assessed in PCOS and control women, by measuring flow mediated dilation (FMD) in the brachial artery.

\section{RESULTS}

LH/FSH ratio, testosterone, fasting insulin levels were significantly higher in PCOS than the control group. The PCOS group was more insulin resistant than age and BMI matched control women (HOMA IR 3.82 \pm 0.48 Vs. $1.23 \pm 0.29$, p $<0.001$ ). Total cholesterol, triglycerides and LDL were significantly higher in PCOS women (TC $156.85 \pm 8.21$ Vs. $138.96 \pm 4.93 \mathrm{mg} / \mathrm{dL}, \mathrm{P}=<0.001, \mathrm{TG} 133.57 \pm 6.9$ Vs. $111.08 \pm 9.95 \mathrm{mg} / \mathrm{dL}, \mathrm{P}=<0.001$, LDL $86.9213 .54 \mathrm{Vs} .73 .10 \pm 5.08, \mathrm{p}=<0.001)$, whereas HDL was lower $(41.73 \pm 1.92 \mathrm{Vs} .43 .80 \pm 1.74$ $\mathrm{mg} / \mathrm{dL}, \mathrm{p}=<0.001$ ) in comparison with controls. UsCRP concentrations were higher in PCOS women than the control group $(1.69 \pm 0.40$ Vs. $1.09 \pm 0.22 \mathrm{mg} / \mathrm{L}, \mathrm{p}<0.001)$, usCRP positively correlated with BMI $(\mathrm{r}=0.609, \mathrm{p}=<0.001)$, HOMA-IR $(\mathrm{r}=0.727, \mathrm{p}=<0.001)$ and testosterone $(\mathrm{r}=0.669, \mathrm{P}=<0.001)$. A significant difference in FMD was found between PCOS and control women $(18.25 \pm 5.5 \%$ Vs. 27.27 $\pm 9.41 \%, P=<0.001)$. FMD negatively correlated with testosterone ( $r=-0.463, p=<0.001)$, HOMA-IR $(r=-0.488, p=<0.001)$ and usCRP ( $\mathrm{r}=-0.323, \mathrm{p}=<0.001)$.

\section{CONCLUSION}

Our data show that young PCOS women have increased levels of usCRP and early impairment of endothelial function measured by flow mediated dilatation of brachial artery.

\section{KEYWORDS}

PCOS, CRP, Endothelial Function.

HOW TO CITE THIS ARTICLE: Neelaveni K, Menon R, Sahay RK, et al. CRP levels and endothelial function in young women with PCOS. J. Evolution Med. Dent. Sci. 2016;5(78):5783-5786, DOI: 10.14260/jemds/2016/1305

\section{INTRODUCTION}

Polycystic ovary syndrome (PCOS) is the most common endocrine disorder among women of reproductive age, the prevalence being $7-10 \% .(1,2)$ PCOS is characterised by chronic anovulation and hyperandrogenism with associated insulin resistance as one of the pathological mechanism of this complex disorder.(3) Now PCOS is considered to be not only a reproductive endocrinopathy but also a metabolic disorder with long term health risks, including cardiovascular risk.(4)

Financial or Other, Competing Interest: None.

Submission 08-09-2016, Peer Review 20-09-2016,

Acceptance 22-09-2016, Published 27-09-2016.

Corresponding Author:

Dr. K. Neelaveni,

Associate Professor

Department of Endocrinology,

Osmania Medical College,

Hyderabad.

E-mail: neelaveni1@yahoo.co.in

DOI: $10.14260 /$ jemds $/ 2016 / 1305$
PCOS women even at an early age have a clustering of cardiovascular risk factors such as obesity, type 2 diabetes mellitus, hypertension, dyslipidaemia.(5)The well-documented presence of increased risk factors has led to suggestions that women with PCOS are at higher risk of cardiovascular diseases.

Central adiposity, dyslipidaemia, and insulin resistance (IR) or impaired glucose tolerance. $(6,7,8)$ have been associated with increased C-reactive protein (CRP) as a surrogate marker for low-grade chronic inflammation. As previously noted, insulin resistance and visceral adiposity are common features of PCOS, and elevated CRP levels have been demonstrated among women affected with this disorder. $(9,10)$

Endothelial dysfunction is possibly the earliest event in the process of atherosclerotic lesion formation, hence, the concept that assessment of endothelial function may be a useful tool to identify preclinical atherosclerosis.(11) Brachial artery ultrasound is a widely used noninvasive measure of endothelial dysfunction. Assessment of endothelial function by measuring flow-mediated dilation (FMD) of the brachial artery 
is currently being regarded as a potential tool for predicting coronary heart disease risk. $(12,13)$

There is conflicting data on endothelial function in PCOS. There is limited data on CRP levels and endothelial function in young PCOS women from India. Hence, this study was designed to evaluate the endothelial function in PCOS and relationship with CRP.

\section{MATERIALS AND METHODS}

In this cross sectional study, sixty young PCOS women presenting to endocrinology clinic of tertiary care teaching hospital, and fifty healthy controls who were matched for age and BMI were enrolled. Diagnosis of PCOS was made according to Rotterdam criteria (after exclusion of other aetiologies like hypothyroidism, hyperprolactinaemia, Cushing's syndrome, congenital adrenal hyperplasia, adrenal tumours and drug related disorders). None of the patients were affected by neoplastic, metabolic or cardiovascular disorders or other concurrent medical illness. Detailed history, physical examination, anthropometry were recorded.

At the study entry, all subjects underwent venous blood samples for hormonal assay, lipid profile, ultra-sensitive CRP (usCRP), fasting plasma glucose and measurement of fasting plasma insulin values. All blood samples were obtained in the morning between 0800 and 0900 hours after an overnight fast during early follicular phase (day 2 to 5 ) of a spontaneous or progesterone induced menstrual cycle. All subjects underwent transabdominal ultrasonography.

Plasma glucose levels were determined by the Glucose oxidase method on a glucose semi-auto analyser. Total cholesterol was determined using the cholesterol esterase method on a semi-automated analyser. HDL cholesterol was determined using cholesterol esterase method following selective precipitation of Apolipoprotein B containing lipoprotein with a polyanion solution. Triglycerides were determined enzymatically as glycerol on a Hitachi semiautomated chemistry analyser after hydrolysis with lipase. All lipid assays had intra and inter assay variation of less than $3 \%$. LDL cholesterol was calculated using Friedewald equation: LDL cholesterol $=$ total cholesterol $-(\mathrm{HDL}+$ triglycerides/5). Ultra-sensitive CRP (usCRP) analysis was carried out using a uSCRP ELISA kit (DSL ACTIVE* - 10-42100).

Serum LH (RIAK 10), FSH, Testosterone (ACTIVE* TESTOSTERONE RIA DSL-4000), DHEA-S (ACTIVE* DHEA-S RIA DSL-3500), 17-hydroxy progesterone (ACTIVE* 17-OH PROGESTERONE RIA DSL-5000) were measured by RIA. TSH and Prolactin were measured by IRMA using IRMAK-9, IRMAK-13 respectively, procured from Board of Radiation and Isotope Technology (BRIT), BARC, Navi Mumbai.

Insulin was determined by double antibody RIA using RIAK-1 procured from BRIT. Insulin resistance was determined by homeostasis model assessment (HOMA-IR). The estimate of IR by HOMA was calculated with the following formula: (Fasting plasma insulin (micro units/mL) x Fasting plasma glucose (mmol/L)/22.5.

\section{Flow Mediated Dilation Measurement}

Sixty (60) PCOS patients and fifty (50) controls underwent brachial artery ultrasound for assessment of endothelial function by examining brachial artery responses to endothelium dependent stimuli. Ultrasonography measurements were carried out according to the method described by Coretti.(14) High resolution ultrasonography by GE VIVID FIVE machine was used to evaluate endothelial function. The assessment was performed after an overnight fast in a quiet air conditioned room by a cardiologist, who was unblinded. A $10 \mathrm{MHz}$ linear phased array ultrasound transducer was used to image the dominant arm brachial artery just above the antecubital fossa. After the detection of the right transducer position, the skin surface was marked and the arm kept in the same position during the study. The diameter of the brachial artery was measured from twodimensional ultrasound images.

Arterial diameters were measured at rest and during reactive hyperaemia. Reactive hyperaemia was induced by inflation of pneumatic cuff on the upper arm to $50 \mathrm{~mm}$ above systolic pressure followed by cuff deflation after 5 minutes. The increased flow in the artery after removal of blood pressure cuff is termed reactive hyperaemia and results in flow mediated dilation (FMD). The diameter of brachial artery was scanned and recorded for the first two minutes after cuff deflation. The end diastolic arterial diameter was measured from one media adventitia interface to the other at the clearest section three times, at baseline, every 20 sec. after reactive hyperaemia. The maximum vessel diameter was defined as the average of the three consecutive maximum diameter measurements after hyperaemia. Vasodilatation by reactive hyperaemia was expressed as the percent change in diameter, compared with baseline values.

\section{Statistical Analysis}

R Programming software (Version 3.0) was used for data analysis. Results were expressed as mean \pm S.D. Differences between means were analysed by student's unpaired test using two tailed tests for significance. $\mathrm{P}=<0.05$ was considered statistically significant. Analysis of the correlation between parameters was performed by using Pearson's bivariate correlation coefficient.

\section{RESULTS}

The age of PCOS women ranged from 18-23 years with a mean of $20.53 \pm 1.32$ years. The age of controls ranged $18-24$ years with a mean of $20.26 \pm 1.31$ years (P value $=0.280$ ). The mean waist circumference though higher in PCOS women than that of control group, did not reach statistical significance (91.23 $\pm 4.2 \mathrm{~cm}$ Vs. 89.01 $\pm 5.41 \mathrm{~cm} \mathrm{P}=0.017$ ), whereas WHR was significantly different $(0.83 \pm 0.01$ Vs. $0.82 \pm 0.01, \mathrm{p}=<0.001)$ as shown in table-1. Among PCOS women, 23.3\% $(\mathrm{n}=14)$ were having normal BMI, $40 \%(n=24)$ were overweight and $36.6 \%$ $(n=22)$ were obese according to WHO cut-offs. Serum Testosterone, LH/FSH ratio was significantly higher in PCOS women than controls.

Although fasting glucose concentrations were not different in both the groups, the fasting insulin concentrations were higher in PCOS women than controls indicating that higher insulin levels were required to maintain euglycaemia. The mean serum levels of total cholesterol, triglycerides, HDL cholesterol and LDL cholesterol were significantly different in PCOS women and controls (Table -1).

UsCRP concentrations were significantly higher in cases than controls. The geometric means for the women with PCOS and the control group were $1.69 \mathrm{mg} / \mathrm{L}$ and $1.23 \mathrm{mg} / \mathrm{L}$ respectively $(\mathrm{P}=<0.001)$. The mean usCRP concentrations were significantly higher in the PCOS subgroups at normal BMI 
$(<25)$, overweight (BMI 25-29.9) and in the obese group (BMI $\geq 30$ ) compared with the control subgroups of similar BMI $(\mathrm{P}<0.001)$ (Table-2). UsCRP positively correlated with BMI $(\mathrm{r}=0.609, \mathrm{p}=<0.001)$, HOMA-IR $(\mathrm{r}=0.727, \mathrm{p}=<0.001)$ and testosterone $(\mathrm{r}=0.669, \mathrm{p}=<0.001)$.

Brachial artery diameter at baseline was similar in both the groups. There was a significant impairment of endothelium dependent (FMD) vascular response in the PCOS women as compared to the controls (Table-3). Endothelium dependent vasodilatation (FMD) correlated negatively with usCRP ( $\mathrm{r}=-0.323, \mathrm{p}=<0.001)$, testosterone $(\mathrm{r}=-0.463, \mathrm{p}=<0.001)$, and HOMA-IR( $\mathrm{r}=-0.488, \mathrm{p}=<0.001)$.

\begin{tabular}{|c|c|c|c|}
\hline & $\begin{array}{c}\text { PCOS } \\
(n=60)\end{array}$ & $\begin{array}{l}\text { Controls } \\
(n=50)\end{array}$ & $\begin{array}{c}P \\
\text { Value }\end{array}$ \\
\hline Age (yrs.) & $20.53 \pm 1.32$ & $20.26 \pm 1.31$ & 0.280 \\
\hline $\mathrm{BMI}\left(\mathrm{kg} / \mathrm{m}^{2}\right)$ & $26.98 \pm 3.36$ & $26.78 \pm 3.30$ & 0.758 \\
\hline $\begin{array}{c}\text { Waist } \\
\text { circumference } \\
(\mathrm{cm})\end{array}$ & $91.23 \pm 4.20$ & $89.01 \pm 5.41$ & 0.017 \\
\hline $\begin{array}{c}\text { Waist Hip } \\
\text { Ratio (WHR) }\end{array}$ & $0.83 \pm 0.01$ & $0.82 \pm 0.01$ & $<0.001$ \\
\hline LH/FSH ratio & $2.88 \pm 0.58$ & $1.41 \pm 0.19$ & $<0.001$ \\
\hline $\begin{array}{c}\text { Testosterone } \\
(\mathrm{ng} / \mathrm{mL})\end{array}$ & $0.71 \pm 0.07$ & $0.31 \pm 0.07$ & $<0.001$ \\
\hline $\begin{array}{c}\text { Fasting Glucose } \\
(\mathrm{mg} / \mathrm{dL})\end{array}$ & $82.9 \pm 8.4$ & $85.6 \pm 7.1$ & 0.042 \\
\hline $\begin{array}{l}\text { Fasting Insulin } \\
(\mu \mathrm{U} / \mathrm{mL})\end{array}$ & $17.14 \pm 2.13$ & $5.80 \pm 1.27$ & $<0.001$ \\
\hline HOMA-IR & $3.82 \pm 0.48$ & $1.23 \pm 0.29$ & $<0.001$ \\
\hline usCRP(mg/L) & $1.69 \pm 0.40$ & $1.09 \pm 0.22$ & $<0.001$ \\
\hline $\begin{array}{c}\text { Total cholesterol } \\
(\mathrm{mg} / \mathrm{dL})\end{array}$ & $156.85 \pm 8.2$ & $138.9 \pm 4.93$ & $<0.001$ \\
\hline $\begin{array}{l}\text { Triglycerides } \\
\text { (mg/dL) }\end{array}$ & $133.57 \pm 6.9$ & $111.08 \pm 9.95$ & $<0.001$ \\
\hline $\begin{array}{l}\text { HDL cholesterol } \\
\text { (mg/dL) }\end{array}$ & $41.73 \pm 1.92$ & $43.8 \pm 1.74$ & $<0.001$ \\
\hline $\begin{array}{l}\text { LDL cholesterol } \\
(\mathrm{mg} / \mathrm{dL})\end{array}$ & $86.92 \pm 13.54$ & $73.1 \pm 5.08$ & $<0.001$ \\
\hline
\end{tabular}

\begin{tabular}{|c|c|c|c|}
\hline BMI (kg/m $\left.{ }^{2}\right)$ & $\begin{array}{c}\text { PCOS } \\
(\mathbf{n = 6 0})\end{array}$ & $\begin{array}{c}\text { Controls } \\
(\mathbf{n = 5 0})\end{array}$ & $\begin{array}{c}\mathbf{P} \\
\text { Value }\end{array}$ \\
\hline$<25$ & $1.18 \pm 0.14$ & $0.86 \pm 0.11$ & $<0.001$ \\
\hline $25-30$ & $1.63 \pm 0.21$ & $1.01 \pm 0.06$ & $<0.001$ \\
\hline$\geq 30$ & $2.08 \pm 141$ & $1.35 \pm 0.14$ & $<0.001$ \\
\hline Table 2: Comparison of usCRP (mg/L) levels in normal \\
BMI, Overweight and Obese Women between PCOS and \\
Controls \\
\hline
\end{tabular}

\begin{tabular}{|c|c|c|c|}
\hline & $\begin{array}{c}\text { PCOS } \\
(n=60)\end{array}$ & $\begin{array}{c}\text { Controls } \\
(n=50)\end{array}$ & $\begin{array}{c}\mathbf{P} \\
\text { Value }\end{array}$ \\
\hline $\begin{array}{l}\text { Baseline brachial } \\
\text { artery diameter } \\
(\mathrm{mm})\end{array}$ & $3.12 \pm 0.15$ & $3.10 \pm 0.16$ & 0.456 \\
\hline $\begin{array}{l}\text { Diameter after } \\
\text { reactive } \\
\text { hyperaemia }(\mathrm{mm})\end{array}$ & $3.68 \pm 0.16$ & $3.93 \pm 0.15$ & $<0.001$ \\
\hline FMD (\%) & $18.25 \pm 5.5$ & $\begin{array}{c}27.27 \pm \\
9.41\end{array}$ & $<0.001$ \\
\hline
\end{tabular}

\section{DISCUSSION}

PCOS is characterised by several biochemical and metabolic alterations including insulin resistance. Insulin resistance is a key component of PCOS. Both lean and obese women with PCOS have peripheral IR and hyperinsulinaemia. $(15,16)$ Decreased insulin sensitivity, and inflammatory cytokines, mainly IL-1, IL-6, and TNF $\alpha$, may exert stimulating effect on hepatic synthesis of acute-phase proteins, such as CRP.(13) Previous studies detected a correlation between IR and CRP concentrations.(6) Asian PCOS women were found to have more insulin resistance than white PCOS women.(17)

This study has shown that CRP concentrations measured using an ultra-sensitive assay is significantly increased in women with PCOS relative to the healthy control women. CRP levels remained significantly higher in PCOS women even after adjusting for BMI. Kelly et al noted increased CRP levels and tissue plasminogen activator (TPA) levels in PCOS women as compared to healthy weight matched controls. However, when adjusted for insulin sensitivity, CRP was no longer significantly different between groups but tPA levels remained significantly different. (9) In another study by Ji Young Oh et al compared hsCRP in normal weight PCOS with controls and they found higher hsCRP levels in PCOS women, but this difference was not significant after adjusting for BMI.(18) N. Boulman et al in their study found that mean CRP conc. were significantly higher in normal and obese PCOS women but in over weight PCOS women CRP conc. though higher than controls did not reach statistical significance.(19) In the Indian context, Karoli R et al(20) reported statistically non-significant elevation in CRP levels, whereas Ramanand SJ et al(21) found significantly elevated CRP levels in overweight and obese PCOS but not in normal weight PCOS women.

The endothelium is highly active metabolically and plays a key role in vascular homeostasis. The healthy endothelium, particularly endothelium-derived nitric oxide, not only modulates the tone of underlying vascular smooth muscle but also inhibits several proatherogenic processes. Hence, endothelial dysfunction is considered to be an early indication in atherogenesis.

Data regarding endothelial dysfunction in PCOS patients are poor and contrasting. In this study, PCOS women demonstrated decreased vascular response to reactive hyperaemia i.e., FMD suggestive of early impairment of endothelial function and also negatively correlated with HOMA-IR, testosterone and usCRP. Similar to our study, Karoli $\mathrm{R}$ et $\mathrm{al}(20)$ found decreased FMD, which correlated negatively with HOMA index and hsCRP in Indian PCOS women. Ilhan Tarkun et al, in their study demonstrated, endothelial dysfunction which was correlated with CRP and insulin resistance in young and normal weight women with PCOS.(22) Francesco Orio et al also demonstrated early impairment of endothelial function in young normal weight, nondyslipidaemic, non-hypertensive women with PCOS. (23)In another study, Paradisi et al observed endothelial dysfunction in obese PCOS women in comparison to age and weight matched controls by using leg blood flow responses to the vasodilator methacholine chloride.(13)

Conversely, Mather et al, using brachial artery ultrasound, found no evidence of endothelial dysfunction in healthy women with PCOS compared with age but not weight matched controls.(24) A S T Bickerton et al also reported normal 
endothelial function and CRP concentrations in women with PCOS compared with age and weight matched controls. (25)

In conclusion, our data shows that young PCOS women have elevated CRP and early impairment of endothelial function. But this study has a limitation of involving small study group. Further, prospective studies with larger number of patients are necessary to confirm our results in the Indian PCOS women.

\section{ACKNOWLEDGEMENTS}

We sincerely express our gratitude to Dr. Raja Sriswan Mamidi, scientist B from National Institute of Nutrition, ICMR, Hyderabad, for his support in the preparation of the manuscript.

\section{REFERENCES}

1. Azziz R, Woods KS, Reyna R, et al. The prevalence and features of the polycystic ovary syndrome in an unselected population. J Clin Endocrinol Metab 2004;89(6):2745-9.

2. Hart R, Hickey M, Franks S. Definitions, prevalence and symptoms of polycystic ovaries and polycystic ovary syndrome. Best Pract Res Clin Obstet Gynaecol 2004;18(5):671-83.

3. Dunaif A. Hyperandrogenic anovulation (PCOS): a unique disorder of insulin action associated with an increased risk of non-insulin-dependent diabetes mellitus. Am J Med 1995;98(1A):33S-9S.

4. Cibula D, Cifkova R, Fanta M, et al. Increased risk of noninsulin dependent diabetes mellitus, arterial hypertension and coronary artery disease in perimenopausal women with a history of polycystic ovary syndrome. Hum Reprod 2000;15(4):785-9.

5. Talbott E, Guzick D, Clerici A, et al. Coronary heart disease risk factors in women with polycystic ovary syndrome. Arterioscler Thromb Vasc Biol 1995;15(7):821-6.

6. Festa A, D'Agostino R, Howard G, et al. Chronic subclinical inflammation as part of the insulin resistance syndrome: the insulin resistance atherosclerosis study (IRAS). Circulation 2000;102(1):42-7.

7. Lundman P, Eriksson MJ, Silverira A, et al. Relation of hypertriglyceridemia to plasma concentrations of biochemical markers of inflammation and endothelial activation (C-reactive protein, interleukin-6, soluble adhesion molecules, von Willebrand factor, and endothelin-1). Am J Cardiol 2003;91(9):1128-31.

8. Frohlich M, Imhof A, Berg G, et al. Association between Creactive protein and features of the metabolic syndrome: $\mathrm{a}$ population-based study. Diabetes Care 2000;23(12): 1835-9.

9. Kelly CC, Lyall H, Petrie JR, et al. Low grade chronic inflammation in women with polycystic ovarian syndrome. J Clin Endocrinol Metab 2001;86(6):2453-5.

10. Fenkci V, Fenkci S, Yilmazer $M$, et al. Decreased total antioxidant status and increased oxidative stress in women with polycystic ovary syndrome may contribute to the risk of cardiovascular disease. Fertil Steril 2003;80(1): 123-7.

11. Verma S, Buchanan MR, Anderson TJ. Endothelial function testing as a biomarker of vascular disease. Circulation 2003;108(17):2054-9.
12. Anderson TJ, Uehata A, Gerhard MD, et al. Close relation of endothelial function in human coronary and peripheral circulations. J Am Coll Cardiol 1995;26(5):1235-41.

13. Paradisi G, Steinberg HO, Hempfling A, et al. Polycystic ovary syndrome is associated with endothelial dysfunction. Circulation 2001;103(10):1410-5.

14. Corretti MC, Anderson TJ, Benjamin EJ, et al, Guidelines for the ultrasound assessment of endothelium dependent flow mediated vasodilation of the brachial artery. A report of the international brachial artery reactivity task force. J Am Coll Cardiol 2002;39(6):257-65.

15. Ehrmann DA, Liljenquist DR, Kasza K, et al. Prevalence and predictors of the metabolic syndrome in women with the polycystic ovary syndrome. J Clin Endocrinol Metab 2006; 91(1):48-53.

16. Ridker PM, Stampfer MJ, Rifai N. Novel risk factors for systemic atherosclerosis: a comparison of C-reactive protein, fibrinogen, homocysteine, lipoprotein(a) and standard cholesterol screening as predictors of peripheral arterial disease. JAMA 2001;285(19):2481-5.

17. Wijeyaratne $\mathrm{CN}$, Balen $\mathrm{AH}$, Barth $\mathrm{JH}$, et al. Clinical manifestations and insulin resistance (IR) in polycystic ovary syndrome(PCOS) among South Asians and Caucasians: Is there a difference? Clin Endocrinol 2002; 57(3):343-50.

18. Oh JY, Ji-Ah L, Lee H, et al. Serum C-reactive protein levels in normal weight polycystic ovary syndrome. Korean J Intern Med 2009;24(4):350-5.

19. Boulman N, Levy $Y$, Leiba R, et al. Increased C-reactive protein levels in the polycystic ovary syndrome: A marker of cardiovascular disease. J Clin Endocrinol Metab 2004;89(5):2160-5.

20. Karoli R, Fatima J, Siddiqi Z, et al. Study of early atherosclerotic markers in women with polycystic ovary syndrome. Indian J Endocr Metab 2012;16(6):1004-8.

21. Ramanand SJ, Ramanand JB, Raparti GT, et al. High sensitivity C -reactive protein (hs-CRP) and clinical characteristics, endocrine, metabolic profile in Indian women with PCOS: a correlation. Int J Reprod Contracept Obstet Gynecol 2014;3(1):118-26.

22. Tarkun I, Arslan BC, Cantürk Z, et al. Endothelial dysfunction in Young women with polycystic ovary syndrome: relationship with insulin resistance and lowgrade chronic inflammation. J Clin Endocrinol Metab 2004;89(11):5592-6.

23. Orio F, Palomba S, Cascella T, et al. Early impairment of endothelial structure and function in young normal-weight women with polycystic ovary syndrome. J Clin Endocrinol Metab 2004;89(9):4588-93.

24. Mather JK, Verma S, Corenblum B, et al. Normal endothelial function despite insulin resistance in healthy women with the polycystic ovary syndrome. J Clin Endocrinol Metab 2000;85(5):1851-6.

25. Bickerton AS, Clark N, Meeking D, et al. Cardiovascular risk in women with polycystic ovarian syndrome. J Clin Pathol 2005;58(2):151-4. 